\title{
The Leap into the New Normal in Creative Work: A Qualitative Study of the Impact of COVID-19 on Work Practices in Industrial Companies
}

\author{
Oscar Pakos* \\ School of Business, Economics and Society, Friedrich-Alexander University Erlangen-Nürnberg \\ Lange Gasse 20, 90403 Nürnberg, Germany \\ E-mail: oscar.pakos@fau.de \\ Jana Walter \\ School of Business, Economics and Society, Friedrich-Alexander University Erlangen-Nürnberg \\ Lange Gasse 20, 90403 Nürnberg, Germany \\ E-mail: jana.walter@fau.de \\ Marc Rücker \\ School of Business, Economics and Society, Friedrich-Alexander University Erlangen-Nürnberg \\ Lange Gasse 20, 90403 Nürnberg, Germany \\ E-mail: marc.ruecker@fau.de \\ Kai-Ingo Voigt \\ School of Business, Economics and Society, Friedrich-Alexander University Erlangen-Nürnberg \\ Lange Gasse 20, 90403 Nürnberg, Germany \\ E-mail: kai-ingo.voigt@fau.de
}

\begin{abstract}
For many employees, the COVID-19 pandemic has precipitated a move from centralized workplaces to full-time teleworking from home. As a catalyst for the virtualization of the working world, the pandemic has accelerated company transformation to digitalization and New Work. In a post-COVID-19 world, companies will face the challenge of combining virtual and physical working while offering employees an appropriate working infrastructure. However, the future consequences for work design remain unclear, as many companies are in a state of flux. The purpose of the present study was to develop an up-to-date overview of what this future New Normal might look like, and to expand existing knowledge in this regard. To that end, we conducted fifteen in-depth interviews with experts from German industrial companies. The findings identify four main areas of change at individual and team levels: the meaning of the work environment, collaboration, creative work, and the nature of future work. The results offer some profound insights into the field of design and virtualization in terms of working location, working time models, and the future of collaborative and creative work. The paper concludes with recommendations for practice and future research.

Keywords: New Work, COVID-19, Physical Work Environment, Collaboration, Creativity, Digital Transformation, New Normal

DOI: $10.7176 / \mathrm{EJBM} / 13-10-01$

Publication date:May $31^{\text {st }} 2021$

\section{Introduction}

The working world is undergoing a period of profound change as the outbreak of the new coronavirus SARS-CoV2 (COVID-19) has abruptly exposed companies in every sector to radically altered circumstances (Diab-Bahman \& Al-Enzi, 2020; Schmidtner, Doering, \& Timinger, 2021). To protect the health of employees, on-site work has had to be suspended or severely restricted, and most employees have had to move quickly to working from home. Depending on business type, technical requirements, and existing implementation of new styles of work, some companies have proved better prepared than others to respond to this crisis (Newman \& Ford, 2021). In particular, companies with no prior experience of employees working from home had to accelerate the introduction of digital infrastructure and new work practices.

The widespread societal and economic disruption caused by the pandemic has raised many questions for the world of work. In particular, managers and employees must develop alternative forms of collaboration to work toward common goals in creative, solution-oriented, and efficient fashion (Schmidtner et al., 2021). To that extent, the COVID-19 crisis has accelerated the digital transformation and evolution of the work environment at an unprecedented pace (Savić, 2020), and this can be expected to have long-term implications for how we work in the future (Davidson, 2020; Umbs, 2020).
\end{abstract}


The suddenness of these developments means that research has not yet had time to investigate these issues from an entrepreneurial perspective. To date, little is known about how companies are dealing with the effects of the crisis on daily work, the impacts on creative knowledge work, or how employers see the future. These issues are central to understanding how companies are changing, and what will be required in order to adapt successfully to the working world of the future. To explore these issues, the present study addresses the following research questions.

1. How has the meaning of physical work environments (PWE) changed during the COVID-19 crisis, and what role will the office and home office play in the future?

2. How has collaboration among employees changed, and how might it look in the future?

3. How does the COVID-19 crisis impact creative work?

To answer these questions, we employed an explorative qualitative research design based on 15 semi-structured in-depth interviews with experts from industrial companies (Gläser \& Laudel, 2010; Kvale, 1996). Our findings contribute to two main strands of the existing literature: the changing meaning of the PWE, including the more specialized future role of the office and home office, and changes in collaborative and creative work at individual and team levels, including the design of future ways of working.

\section{Theoretical background}

\subsection{Digital transformation of work}

Digitalization is currently considered the most important driver of change in the working world (Harteis, 2018). By defining new technological baselines and creating opportunities for cooperation, production, company organization, and the distribution of goods and services, digitalization affects organizations and employees in every sector (Parviainen, Tihinen, Kääriäinen, \& Teppola, 2017). This impacts directly on work tasks and processes and has the potential to change them fundamentally (Harteis, 2018). This so-called digital transformation of work includes the transition from analog to digital work processes, the introduction of new types of digital working, and applications networking, along with the resulting potential changes in society (Hildebrandt, Kluge, \& Ziefle, 2020).

The digital technologies driving this transformation in work design (Manca, Grijalvo, Palacios, \& Kaulio, 2018) have radically altered the methods and content of industrial work (Johansson, Abrahamsson, Kåreborn, Fältholm, Grane, \& Wykowska, 2017). The integration of cyber-physical systems in the Internet of Things and Services means that production processes are becoming increasingly automated. As well as flexible robotic technologies and associated new forms of interaction and division of labor between humans and machines (Gale, Wojan, \& Olmsted, 2002), digital assistance systems such as data glasses or VR/AR applications can provide employees with situation-specific information for local and remote activities and service delivery (Schwarzmüller, Brosi, Duman, \& Welpe, 2018).

In knowledge work contexts, mobile devices are routinely used in many organizations as a standard component of flexible daily work (Jensen, 2018), providing technical support for the preparation and processing of previously unmanageable volumes of information and data (Mohammad, 2009). Technologies such as cloud computing and big data analytics with visualization tools increase control over work processes and facilitate more thorough decision-making (Schwarzmüller et al., 2018). Increasingly, artificial intelligence applications support and enhance complex activities, in some cases enabling computers to take over completely (Bødker \& Sundblad, 2008; Vargo, Zhu, Benwell, \& Yan, 2020). Communication and collaboration applications are also increasingly common, changing how employees interact, often in virtual environments (Davis \& Bryant, 2003; Kaushik \& Guleria, 2020).

These changes also impose new demands on employees' technological and methodological competencies (Gale et al., 2002). In particular, digital working requires enhanced situational adaptability, intuition, creativity, problem-solving, interpersonal interactions, and persuasiveness (Kötting, 2019), and the accelerating pace of change makes lifelong learning and continuous development of these competencies increasingly important (Oberländer, Beinicke, \& Bipp, 2020; Senge, 1990). To be successful in the long-term, companies need employees who can think innovatively and disruptively and work, decide, and act digitally (Van Laar, van Deursen, van Dijk, \& de Haan, 2020), as well as managers who are proficient in digital leadership and self-management (Newman \& Ford, 2021; Schmidt, 2014).

Industry is currently exceeding the threshold at which digitalization becomes central to work and value creation. Simultaneously, innovation cycles are becoming shorter, and the rapid and efficient development of multiple technologies makes new applications possible (Amabile, 1988; Stalk, \& Hout, 1990). As a consequence, there is no end in sight to the digital transformation of work.

\subsection{New Work}

Driven by digitalization and the accompanying processes of profound change at societal and economic levels, our understanding of work is also being transformed (Manca et al., 2018). The resulting developments can be subsumed under the concept of New Work (Gerards, de Grip, \& Baudewijns, 2018; Senge, 1990). Given the 
multiple possible interpretations of New Work, there is as yet no uniform definition of the term (Stoepfgeshoff, 2018). In general, however, New Work is currently understood as the shift toward more flexible and forwardlooking work practices (Umbs, 2020) and innovative office concepts (Gerards et al., 2018). This foregrounds the needs and skills of employees, as well as the benefits for companies of new technology-based approaches and the resulting productivity (Umbs, 2020).

Three of the main characteristics of New Work are flexibility, agility, and new office concepts. As these have significant implications for collaboration and creativity, they are of particular interest here. Figure 1 summarizes these main elements and their content.

\begin{tabular}{|l|l|l|}
\hline Flexibility & Agility \\
\hline - Local & Temporal & Agile methods \\
\hline & Flat hierarchies \\
\hline
\end{tabular}

Figure 1. Elements of New Work.

Flexibility. Among the key elements of New Work, making work more flexible is perhaps the most progressive (Härenstam, 2005; Maravelias, 2009; Nediari, Roesli, \& Simanjuntak, 2021; Ollo-López, BayoMoriones, \& Larraza-Kintana, 2011) and primarily involves the implementation of local and temporal flexibility in various forms (Bailey \& Kurland 1999; Halford, 2005). In particular, the digitalization of service and production processes, the use of information and communication technologies, and practices such as home and mobile working allow employees to choose their own work location, which is becoming increasingly important (Blok, Groenesteijn, Schelvis, \& Vink, 2012). In addition, working time models such as "trust-based working hours" allow employees to schedule their own work, reflecting the desire to balance work with family and leisure time (Gray, Hudson, \& Gordon,1996; Madsen, 2003). One common side effect of these developments is a more fluid transition between work and private life (Moll \& Leede, 2016).

Agility. The increased use of flexible methods of working and organizing means that companies must be able to react as quickly and innovatively as possible to changing market conditions and customer needs. To do so, companies rely on agile models and working methods (O'Reilly \& Tushman, 2013) such as Scrum, Kanban, and Design Thinking (Stahl, 2019). Hierarchical structures are being replaced by task-oriented, project-based organizational forms characterized by interdisciplinary teams and flat hierarchies (Avolio, Walumbwa \& Weber, 2009; Koclowksi, 2010). In tandem, there is a move away from control-based leadership toward trust-based, results-oriented collaboration and participative decision-making mechanisms (Avolio et al., 2009). This agile way of working builds employees' sense of autonomy in their daily work (Gerdenitsch, Korunka \& Hertel, 2018; Haapakangas, Hallman, Mathiassen, \& Jahncke, 2018; Koclowski, 2010) but also requires the ability to selforganize (Kim, Candido, Thomas, \& de Dear, 2016).

New office concepts. As traditional offices cannot readily support these new ways of working, New Work also entails changes in the PWE (Leede \& Nijland, 2016; Nediari et al., 2021). Instead, non-territorial office concepts such as Desk Sharing (Elsbach \& Bechky, 2007), Shared Desk (Millward, Haslam, \& Postmes, 2007), or Hot Desking (Babapour, Karlsson, \& Osvalder, 2018; Millward et al., 2007) reduce the ratio of workstations to employees. Under these new workplace concepts, employees have no fixed workplace but must always look for a new one, adhering to a Clean Desk policy (Ross, Ressia, \& Sander, 2017). In this way, workspaces are used more efficiently and companies can expect to reduce costs (Pérez, Sánchez, \& de Luis Carnicer, 2002). In addition, the principle of Activity-based Working (ABW) is widely used in these non-territorial offices, which are designed to optimize support for employees across diverse tasks and activities (Appel-Meulenbroek, Groenen, \& Janssen, 2011). By providing a main open-plan area and a range of activity-related workspaces for individuals or teams (Eismann, Pakos, Rücker, Meinel, Maier, \& Voigt, 2021; Wohlers \& Hertel, 2018), this design allows employees to choose a suitable workspace for the task in hand. So-called Coworking Spaces push these concepts to extremes, where individual freelancers and, increasingly, employees with different corporate affiliations share common office spaces and infrastructure (Leclercq-Vandelannoitte \& Isaac, 2016).

Changes in collaboration. The flexibilization of work, less hierarchical structures, and the redesign of PWEs also change the nature of employee collaboration and interaction, and technology facilitates networking and collaboration independent of time and place (Kim et al., 2016). However, the potential for more efficient collaboration (Colbert, Yee, \& George, 2016) also poses challenges for team cohesion (de Leede \& Nijland, 2016). Additionally, relationships between managers and employees change in agile organizations, where collaboration is based on mutual trust (Baruch, 2001; Tschannen-Moran \& Hoy, 2000), and employees are encouraged to act independently and to take responsibility for themselves (Busse \& Weidner, 2020). The implementation of ABW also facilitates intra- and inter-departmental collaboration by promoting communication (Babapour et al., 2018; Haapakangas, Hallman, Mathiassen, \& Jahncke, 2019). 
Impacts on creativity. Increasing organizational flexibility and agility gives employees greater freedom in terms of decision making and self-determination, encouraging and challenging them to think creatively (De Paoli \& Ropo, 2015). Additionally, the increasing use of new working methods like Design Thinking accelerate the creative process and promote new user-centered approaches to problem-solving (Gale, 2002). Activity-based office layouts have the potential to foster a company culture of innovation (Kegel, 2017) by introducing diverse spaces that are designed to stimulate creativity by varying elements such as light and acoustics (AppelMeulenbroek et al., 2011; Meinel, Maier, Wagner, \& Voigt, 2017). Some rooms are designed and equipped to support creative work with appropriate materials (Gerdenitsch et al., 2018) while open-plan areas encourage mutual inspiration and creativity through intensive exchange between employees (Kok, 2016).

\section{Methodology}

\subsection{Research setting}

The present study employed an explorative qualitative design based on in-depth interviews and multiple case studies. This approach was considered appropriate because few academic studies to date have explored the impact of the COVID-19 crisis on corporate work practices, and these novel and complex developments should be studied in their real-world context (Yin, 2018). A qualitative approach also enabled us to gather in-depth information to answer the relevant "how" and "why" questions (Stokes \& Bergin, 2006; Yin, 2018) with a view to developing a detailed understanding of underlying causes and to generate new theoretical knowledge based on individual samples (Eisenhardt \& Graebner, 2007).

The empirical component of the study is based on semi-structured in-depth interviews with experts. This exploratory approach allows structured data collection while maintaining the principle of openness to generate new knowledge (Brinkmann \& Kvale, 2018; Mayring, 2016; Yin, 2018) and conducting, processing, analyzing, and evaluating the interviews in iterative fashion (Gioia, Corley, \& Hamilton, 2013; Kvale, 1996). In selecting the sample, we followed Yin's (2018) recommendation, applying a replication logic to guard against the possible negative effects of sampling bias on the study results.

To acquire the relevant data, we interviewed several experts from industrial companies. To ensure their ability to report on changes in creative work, we selected knowledge workers who work in an innovation environment and whose work has a creative component. Some of the selected experts were managers with the necessary strategic vision and innovative and creative expertise; the remainder were team members who could describe concrete changes in daily operations and personal experiences of everyday work.

To obtain a broader picture of the changes arising from COVID-19, participants were drawn from companies of different sizes. The decision to rely on multiple cases ensured greater rigor, robustness, and reliability (Eisenhardt, 1989). Additionally, the results of multiple case studies can more readily be generalized, as there are fewer context-specific dependencies (Yin, 2018).

\subsection{Sample}

In total, the sample comprised fifteen experts, who were interviewed during September and October 2020. This includes six participants working in the automotive industry (40\%), four from the electrical industry (27\%), two from the consumer goods industry $(13 \%)$, two from the information and communications technology industry $(13 \%)$, and one who worked for an industrial service provider (7\%). As mentioned above, the participants worked for companies of varying sizes. Figure 2 shows the sample distribution in terms of number of employees and company sales. Most of those interviewed (80\%) worked for companies currently employing more than 10,000 people, of which $67 \%$ generated sales revenues of between 10 and 200 billion euros in 2019 .

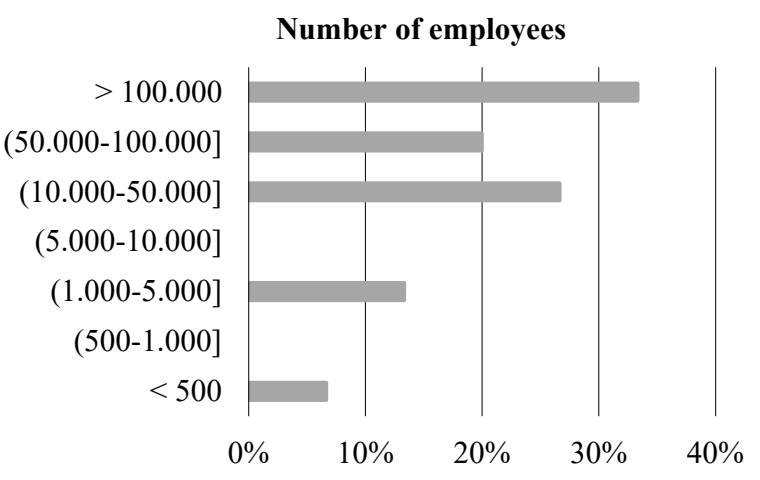

Percentage of companies surveyed
Sales 2019 (in million EUR)

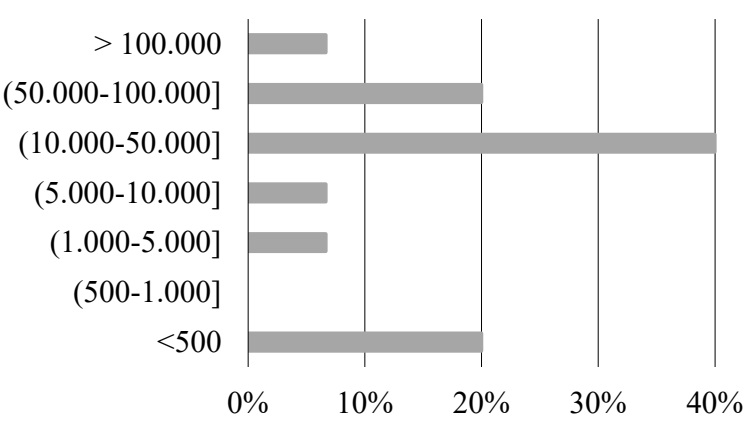

Percentage of companies surveyed

Figure 2. Case companies: Number of employees and sales figures. 
Table 1 provides summary details of individual interviewees; for reasons of confidentiality, all names are anonymized.

Table 1. Summary details of interviewees

\begin{tabular}{rlllllc}
\hline$\#$ & $\begin{array}{l}\text { Management } \\
\text { level }\end{array}$ & $\begin{array}{l}\text { Tenure } \\
\text { (years) }\end{array}$ & Industry & $\begin{array}{l}\text { Number } \\
\text { employees (2019) }\end{array}$ & $\begin{array}{l}\text { Sales } \\
\text { (in Mio. } \mathbf{~} \text { ) }\end{array}$ & $\begin{array}{c}\text { Duration } \\
\text { (min) }\end{array}$ \\
\hline $\mathbf{1}$ & High & 17 & Consumer goods & $1,000-5,000$ & $100-500$ & 43 \\
$\mathbf{2}$ & Expert & 5 & Automotive & $50,000-100,000$ & $10,000-50,000$ & 47 \\
$\mathbf{3}$ & Middle & 2 & Automotive & $10,000-50,000$ & $5,000-10,000$ & 52 \\
$\mathbf{4}$ & Middle & 1 & Automotive & $1,000-5,000$ & $100-500$ & 42 \\
$\mathbf{5}$ & Expert & 0.5 & Automotive & $10,000-50,000$ & $10,000-50,000$ & 47 \\
$\mathbf{6}$ & Middle & 17 & Electronics & $>100,000$ & $50,000-100,000$ & 39 \\
$\mathbf{7}$ & Middle & 18 & ICT & $>100,000$ & $10,000-50,000$ & 48 \\
$\mathbf{8}$ & High & 13 & Electronics & $10,000-50,000$ & $1,000-5,000$ & 37 \\
$\mathbf{9}$ & Middle & 1 & ICT & $>100,000$ & $>100,000$ & 40 \\
$\mathbf{1 0}$ & Middle & 3 & Automotive & $50,000-100,000$ & $10,000-50,000$ & 53 \\
$\mathbf{1 1}$ & High & 25 & Automotive & $1,000-5,000$ & $100-500$ & 45 \\
$\mathbf{1 2}$ & Expert & 7 & Electronics & $>100,000$ & $50,000-100,000$ & 40 \\
$\mathbf{1 3}$ & Expert & 1 & Consulting & $<1,000$ & $<50$ & 37 \\
$\mathbf{1 4}$ & Expert & 2 & Electronics & $>100,000$ & $50,000-100,000$ & 39 \\
$\mathbf{1 5}$ & Middle & 4 & Consumer goods & $50,000-100,000$ & $10,000-50,000$ & 58 \\
\hline
\end{tabular}

\subsection{Data collection and analysis}

We conducted the interviews over a period of two months, by telephone or as virtual meetings, using an interview guide based on the research questions. In keeping with the study's exploratory nature, the guide followed the principles of openness and flexibility to allow for the emergence of unexpected or novel themes (Magnusson \& Marecek, 2015; Misoch, 2019). The interviews comprised three parts. To begin, a few general questions were asked to confirm the interviewee's expertise and reliability, and to establish a common understanding of New Work and the company's level of maturity in that regard. The second part included specific questions about changes in the PWE, collaboration, and creativity, understanding of the processes of transformation, and similarities and differences at individual, team, and organizational levels. In the third and final part of the interview, participants were asked to describe the pandemic's implications for the future, which concepts they thought should be retained or discarded, and how they envisioned work in the future.

To facilitate analysis and evaluation, all interviews were audio-recorded and subsequently transcribed. Following Miles, Huberman, and Saldaña (2020), the transcribed material was subjected to qualitative content analysis. For this purpose, we employed Gioia et al.'s (2013) scientifically recognized and recommended method, which is based on categorization and coding. This procedure involved three steps. First, we organized the literal statements from the transcripts in relation to the interview guide questions, dividing them into meaningful sections and paraphrasing them. From the individual paraphrases, we formed inductive categories that differed at first glance. In the second step, we reviewed the resulting categories across all transcripts to identify commonalities and differences; where possible, these were further summarized to develop subcodes. We then examined the new thematic blocks for interrelationships and deeper structures in light of the research objectives. Finally, in the third step, the subcodes were unified into superordinate categories (Gioia et al., 2013).

Next, we conducted a frequency analysis following Holsti (1968), recording how often the individual interviewees referred to particular issues. This enabled us to infer the relevance of the emerging topics in relation to a given question. The analysis yielded a comprehensive data structure that proves rigorous on closer inspection. On that basis, we developed concepts to describe and explain the observations made during the expert interviews as the basis for a grounded theoretical framework linking the various concepts and addressing the research questions, taking account of all the main emerging categories, subcodes, and superordinate categories, as well as their dynamic interrelationships (Gioia et al., 2013).

To further strengthen the theory, we sought to ensure its validity and to strengthen the foundation for emerging themes and their relationships by triangulating the expert testimonies with secondary data wherever possible (Maxwell, 2013; Yin, 2018). 


\section{Findings}

4.1 Changed meaning of the physical work environment

Office. The expert interviews revealed that the COVID-19 crisis has triggered a tangible change in how PWEs are viewed, focusing in particular on the importance of the office and the home office. Before the outbreak of COVID19,12 of those interviewed assigned central importance to the office as daily work venue and meeting point for collaboration with colleagues.

Before the pandemic, I guess, the office and the exchange with colleagues there was taken for granted. (Expert \#14)

However, according to 10 respondents, decreasing presence in the office and the ability to work virtually from home has diminished the office's importance as a place of work during the pandemic. On the other hand, 6 interviewees said that the office has become much more important as a place to meet, and that they value face-toface meetings with colleagues more than before.

I think the biggest change for me was that I suddenly saw how valuable this office interaction actually is. (Expert \#13)

Only 2 interviewees felt that the office was only one of several work locations even before the pandemic as a result of mobile working habits; for them, work had hardly changed. These findings are summarized in Figure 3.

Before the pandemic

During the pandemic

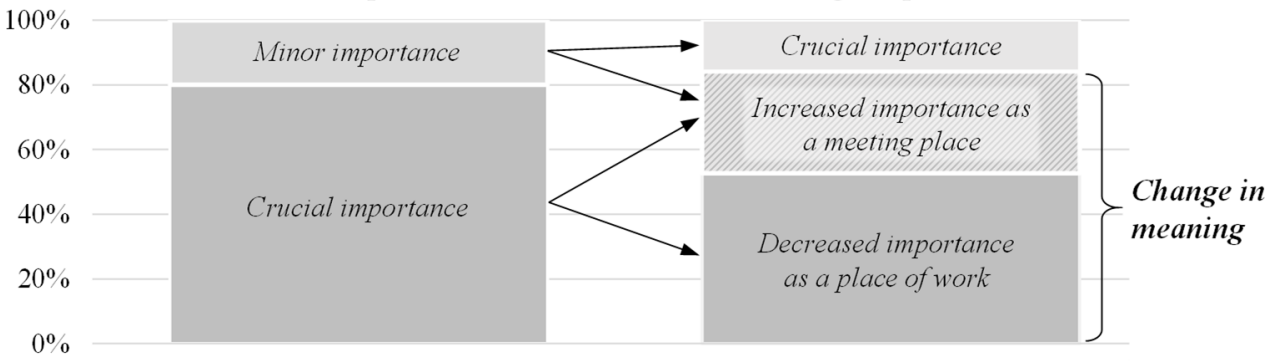

Figure 3. How the importance of the office has changed.

Home office. With the relocation of work to the home office, the role of the private environment as a place of work has also changed. Overall, all 15 of the interviewees felt that the home office would become very important in the future. Three interviewees suggested that organizations are increasingly willing to offer the option of homebased work because of positive experiences to date.

Companies are now much more willing to admit this. Many companies were reluctant to allow home working because they were unsure whether people could be trusted [...] Now, however, most companies have had good experiences. (Expert \#11)

Eight employees saw advantages in a private work environment. In future, they hoped that activities requiring concentration or individual work, such as pure concept development, could be performed from home.

I think a lot of people have realized that the home office is an efficient way of being able to focus and work on certain tasks in a concentrated way. (Expert \#14)

Office environments: Benefits and requirements. Although these results indicate a decline in the office's importance as a place of work and a simultaneous increase in the importance of home-based work, it was clear that all of those interviewed still regarded the office as necessary. Figure 4 summarizes the benefits of office environments and the associated requirements.

From an individual perspective, some interviewees said they come to the office primarily to use on-site facilities such as specialized workshop rooms or quiet zones $(n=5)$, or to use equipment and services that are not available to them at home $(\mathrm{n}=7)$. For that reason, they expressed a need for an excellent office infrastructure that includes utilities $(n=8)$ and adequate technical equipment for all activities $(n=8)$. To accommodate employees' diverse interests and the different tasks that arise during their working day, the office environment should also offer different work zones and flexible switching $(\mathrm{n}=10)$.

From time to time, there are situations where I say, "Okay, I prefer the office as a workplace" simply because

I can access the infrastructure I need, such as a workshop room or IT equipment that I don't have at home. (Expert \#3)

At team level, the increasing importance of the office as a meeting place was again clear. Interviewees valued the office for both professional $(n=5)$ and informal $(n=4)$ exchange and felt that personal contact was essential for strengthening team solidarity and identity $(n=5)$. To foster exchanges between employees, organizations must provide sufficient space for informal meetings $(n=5)$ and for professional collaboration $(n=4)$. Meeting rooms should be flexible $(n=6)$ and should support both formal and informal teamwork $(n=4)$. In addition, it was considered important to have access to various creative tools $(\mathrm{n}=11)$ and technical options to facilitate work $(\mathrm{n}=$ $6)$. 
I believe that trustworthy cooperation depends on getting to know each other personally. [...] That means personal exchange is indeed important, [and] there are topics that can basically only be handled through personal meetings. (Expert \#6)

From an organizational perspective, the office remains important as a physical representation of the company's identity $(n=3)$. In addition, it should serve as a point of contact for employees at all times $(n=3)$ and should help them to identify with the organization and with corporate values $(n=7)$. To achieve this, the office's design must be appealing, flexible, and open, creating an atmosphere that employees find comfortable $(\mathrm{n}=6)$.

In my case, the physical work environment is definitely a focal point for strengthening the corporate culture and leveraging this for branding purposes. (Expert \#9)

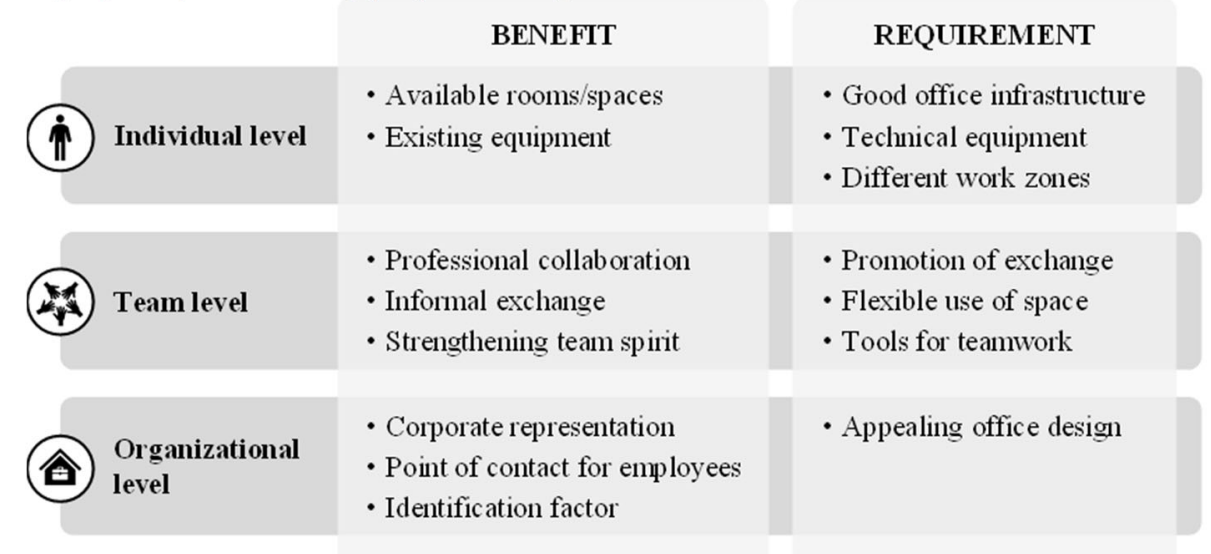

Figure 4. Office environments: Benefits and requirements at various levels.

\subsection{Changes in collaboration}

During the COVID-19 crisis, both the workplace and ways of working have changed for many knowledge workers. In particular, collaboration could no longer occur on-site as before and depends instead on new digital channels.

Communication and coordination. New regulatory restrictions mean that almost all teams $(n=14)$ have had to fundamentally alter their methods of communicating. In particular, digital communication and collaboration tools like Teams, Skype, or Zoom are now routinely used for both professional and informal exchanges.

New communication channels were added, and they are being used. However, this required a bit of renorming - which channel is right for which topic? (Expert \#3)

Only one interviewee saw no change in communication, as he was already working mostly in a virtual team.

According to a majority of participants $(\mathrm{n}=9)$, the new conditions forced teams to find new ways of coordinating. Regular meetings to coordinate and distribute tasks were previously conducted in person but now had to be conducted through digital channels. In addition, some teams introduced new regular appointments to maintain contact more deliberately. Agreements previously made rapidly across desks now tend to involve short calls or chat messaging. In meetings, the loss of direct visual contact has led in some cases to new rules to support increased moderation and organizing efforts.

For example, we have an early-morning team gathering three times a week [...], where we get together virtually to discuss current developments and internal or external matters. (Expert \#15)

In contrast, six teams that were already using digital tools or hybrid forms of consultation for coordination reported almost no changes regarding coordination.

Personal impact. These changes in how teams work have had both positive and negative effects on collaboration (see Figure 5). At a personal level, two interviewees observed that the changed work situation had created a new kind of trust culture and strengthened the desire for active participation in the team. In addition, they felt that communication among themselves was now friendlier and more open-minded. According to four participants, work disruptions caused by family or other personal circumstances are treated with greater understanding and tolerance. One interviewee said that employees are less concerned about conversations disturbing their colleagues and can communicate freely in their home office.

This will to collaborate, to meet, and to exchange [is] stronger than ever because nobody wants to be in a silo-everyone wants to be part of a team. (Expert \#15)

Despite these positive effects and the many efforts to maintain communication through virtual equivalents, six participants referred to a longing for personal contact with colleagues. In particular, they miss the informal and spontaneous conversations during breaks or incidental encounters in the office, which were also seen to make an important contribution to team cohesion. In addition, one interviewee noted that working individually or in small groups can disconnect you from the team. 
[...]You also lost contact with your teammates pretty quickly. [...] making it extremely difficult to keep the team together because you just didn't see people anymore. (Expert \#2)

Professional impacts. Regarding professional collaboration, there was evidence of a slight increase in efficiency. According to two interviewees, virtual communication is now always consciously initiated, focused, and goal-oriented and is confined to essential matters within fixed timeframes. In addition, five interviewees indicated that virtual working has eliminated the time loss associated with changing room or location, and the available time is now used more efficiently for professional exchanges.

Well, first of all, I exchange information differently. When I have a call, it's much more targeted because I

have maybe half an hour for the call, during which I have to ask about everything I want to know. (Expert \#9)

On the other hand, collaboration is made more difficult by the limitations of digital working methods. According to four participants, the interactive possibilities of face-to-face meetings (such as manual use of whiteboards) are lost in the virtual world, and the available tools support only limited active participation. Three respondents noted that important non-verbal information in the form of gestures and facial expressions is also lost in the absence of visual contact, which can lead more quickly to misunderstandings. While this secondary information can be partly conveyed by video, its quality is not comparable.

In fact, collaboration now means pushing workshop participants more to encourage them to participate.

Interaction on a digital whiteboard differs from physical space. (Expert \#10)

Organizational impacts. From an organizational perspective, two interviewees felt that the elimination of location changes and spontaneous meetings helps to keep appointments on time. In the case of distributed teams, one interviewee felt that virtualization of team meetings increases participation, as there are no changes of location to be scheduled. According to two participants, another positive effect of this form of collaboration is that everyone attending a meetings participates in the same way, as even distant or international colleagues feel equally integrated.

Of course, if you're physically in the room and someone is virtually connected, you don't pay much attention to that person. Now that everyone is familiar with virtual meetings and feels more integrated, willingness to collaborate more in the future by virtual means is also likely to increase. (Expert \#2)

However, one interviewee suggested that distance between team members can also inhibit collaboration if virtual contact involves too much effort, tempting them to omit brief but important consultations.

[Previously,] when someone was working on something of interest, you could look over their shoulder. That has become more difficult, as has supporting each other quickly, and that inhibits collaboration. (Expert \#12)

\section{POSITIVE EFFECTS}

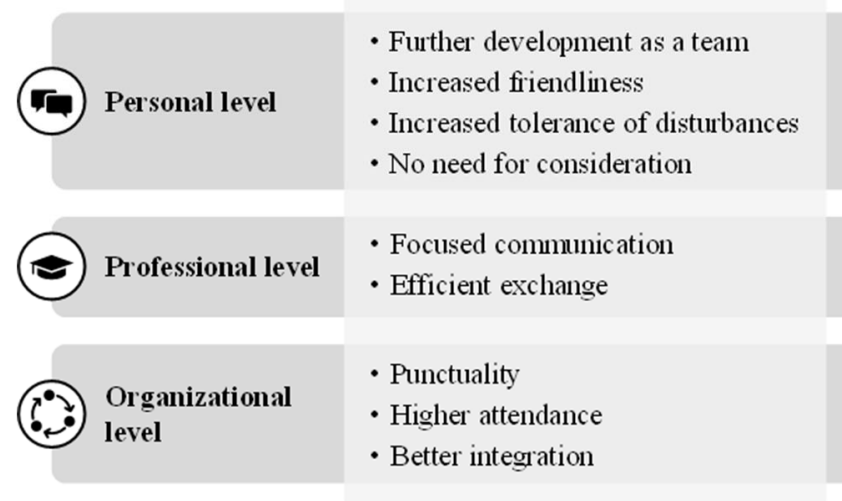

NEGATIVE EFFECTS

- Missing of personal contact

- Lack of informal communication

- Disconnection of the team

- Loss of interaction in meetings

- Loss of side information

- Inhibition due to distance

Figure 5. Impacts on collaboration.

Dependence on team intimacy. With regard to the pandemic's effect on collaboration, it is especially interesting that six interviewees distinguished between newly formed teams and those whose members already knew each other personally before the pandemic. In their experience, virtual collaboration works better in teams that have already worked together physically, as any negative effects are less likely or can be more easily mitigated.

It's easier to work together in a trusting and good way if people have already physically collaborated. I think it's harder [to collaborate with people] on projects that commenced after the closure period if you haven't had a chance to get to know each other in a physical environment. (Expert \#7)

\subsection{Impact on creativity}

Uncertainty. The nature of creative work has been strongly influenced by current changes in the world of work. First, the pandemic-related economic crisis and the restrictions on companies and society have created great uncertainty for employees, and three participants felt that this constrained creativity.

Apart from the fact that all employees have become insecure — which affects the entire organization — [...] this 
multidimensional field of influence naturally affects people emotionally [...] leading to uncertainty in many areas, and creativity suffers, of course. (Expert \#1)

At the same time, creative work is also influenced by the necessary transformation of business processes. For present purposes, we focused on how the virtualization of work and associated changes in location and time have affected creative work.

Virtualization of work. As a consequence of virtualization, creative work must depend on new channels. All fifteen interviewees reported that the PWE was an important source of creativity before the pandemic. Interactive workshops facilitated creativity through exchange with others, using tools like whiteboards, post-its, and a range of creativity techniques. During the lockdown, these physical resources were for the most part no longer accessible. At the outset, there was uncertainty about how creative work could be successfully sustained, and face-to-face meetings had to be canceled. However, ten of the case companies quickly identified solutions that supported virtual creative workshops, including communication and collaboration tools like Mural, Miro or Teams. According to seven interviewees, these tools are fundamental resources for creativity work in virtual teams and beyond.

I'm always experimenting a bit to see what I can transfer to the virtual world, so I have a flipchart or whiteboard to scribble on. We're testing various digital solutions, and we're getting better and better. We're also finding ways of transferring these to the virtual world, but there are inevitable limits. (Expert \#3)

According to our interviewees, these changes in working methods have had only negative effects on creative work at both individual and team levels (see Figure 6). Four participants noted the negative impact on individual employees working from home, whose sense of isolation from their colleagues results in a loss of mutual inspiration and direct feedback. Three participants said they miss the active physical aspects of on-site creative work, and two said that the use of digital tools makes creative processes like brainstorming or prototyping more difficult.

For me personally, this lack of mutual exchange and inspiration in the digital world doesn't work as well as when I am physically working with people. (Expert \#14)

Because individual employees tend to work in a disconnected way, this also interrupts the team's joint creative process and the group dynamic, which four participants felt was crucial for team creativity. One participant said that the use of digital tools increases the organizational effort invested in creative workshops, and five felt that this increases the difficulty of implementation. Because of limitations in relation to communication, methodology, and active participation, participants did not believe that a creative workflow of comparable intensity could be achieved. In addition, it was considered impossible to ensure the continuous presence of all participants, as attention span tends to be shorter for pure screen-based work.

I think the need to concentrate so much on the screen makes the work monotonous. So, in fact, you can only be as creative as the computer allows [...] while I think it was more varied before [in the office]. (Expert \#9)

Impacts at individual level
Decoupled work mode

Figure 6. Impacts of virtualization on creative work.

In light of the above effects of virtualization, six of the interviewees perceived an overall deterioration in the outcomes of creative work. However, it was also emphasized that this depends on the hardware and software used, as well as on the intimacy level of team members as described earlier.

Change in place and time. Along with the shift of location from the physical workplace to the home office, more flexible scheduling and recording of working hours has given employees greater freedom to manage their daily lives, with a more fluid transition between work and private life (work-life blending). The positive and negative effects of these changes on creative work are summarized in Figure 7. Participants differed in their opinions about the effects of workplace relocation. While the effects on individual creative work were generally considered positive, the effects on teams' creative work were perceived as negative. Eight respondents appreciated the calm atmosphere of home-based work as beneficial for concentration and the development of ideas. In addition, five participants said that employees feel more comfortable, inspired, and creative when they can adapt their PWE to their individual needs and working methods.

However, teamwork is made more difficult by physical distance. Three participants noted in particular that joint processes of flow and idea generation suffer in the absence of personal collaboration and interactive methods of working. According to one interviewee, familiarization with new topics or integration into new teams is perceived as more difficult when isolated at home. Additionally, two participants said that family members or personal issues 
can cause disruption and distractions that interrupt thought processes when working from home.

There are also creative tools or tools for creative work that can be used in the home office with colleagues.

[...] If these [...] are state of the art, I believe that creative work can be accomplished very well [virtually].

However, the quality of creative ideas and outputs is never $100 \%$ the same as when people come together in a physical location. (Expert \#1)

More flexible working hours also have both positive and negative effects on creative work. Four interviewees noted that employees can adjust their working day to their individual performance curve and preferred work mode, and three said that, as a result, mental blocks and interrupted thought processes can be avoided. Additionally, five participants felt that employees can change their perspective and generate new or unexpected ideas by taking more frequent breaks to engage in sports or household activities. Two participants also noted that employees feel fresher and more creative when they take more frequent breaks and do not have to commute.

I feel good when I do something different from time to time [instead of working]. [...] If you sit at your desk for 8 to 9 hours and work in the same environment, with the same smells and background noises, your brain is constantly exposed to the same influences. (Expert \#5)

On the other hand, three interviewees pointed out that flexible working hours challenge employees to create a working framework that balances work and private life. For example, two interviewees suggested that irregular breaks and low self-discipline can have a negative effect on creativity. Two also observed that working in a private environment can make it difficult to reconcile the demands of family and work, especially during lockdown.

In general, when personal and professional life are completely blurred. [...] And there is no distance from the job, I don't think that is always good for performance. I believe that distance from the job is important, not only for personal relaxation but also for the free association of thoughts or the appearance of ideas, which in turn promotes creativity. (Expert \#7)

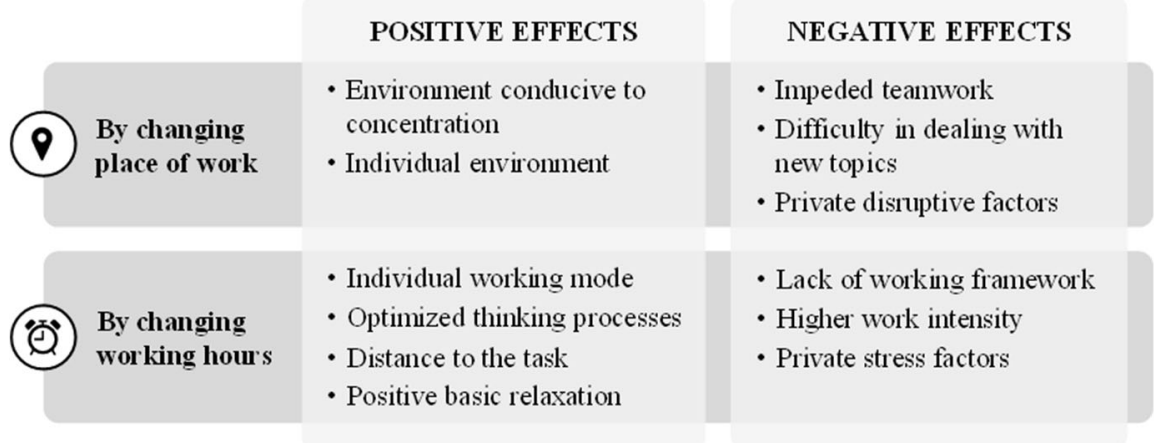

Figure 7. Effects of changes in working place and time.

These conflicting perceptions and the diversity of influencing factors make it difficult to draw clear conclusions about the impact of work-life blending on performance. However, it seems clear that the individual employee's living conditions, spatial and technical resources, and personal working style determine how working from home affects creativity.

\subsection{Impact on future work}

The sudden outbreak of the pandemic posed unprecedented challenges for organizations in every sector. In response, they have reacted quickly by adjusting the PWE, with significant implications for collaboration and creativity. In this section, we consider what employees and organizations have learned so far and the implications of these changes for the future of work.

Learning experiences. During the interviews, all participants referred to both positive and negative experiences, but the former clearly predominated. Figure 8 summarizes their accumulated learning experiences at employee and organizational levels. Nine of our interviewees were surprised to find how well working almost completely from home suited them personally. Four gained valuable experience of mobile and virtual working, and two said that their previous concerns about working in a private environment were allayed by their own positive experiences. For eight participants, the freedom of the home office proved very advantageous for balancing work, family, and leisure. In addition, two noted that a heightened awareness of personal needs related to work increases satisfaction and well-being, leading in turn to better performance.

We have now seen and learned for the first time what it is like to have a home office, and how you can create a balance between private life and job. (Expert \#5)

However, two interviewees contended that the home office was not a permanent solution for the future. Eight highlighted the loss of personal contact with colleagues, and four referred to the associated negative effects on team spirit. Five suggested that differing workloads make it difficult to separate work and private life in a longterm home office setting, with negative consequences for work-life balance. 
Because [employees] are sitting at home and have no social interaction, they are likely to work all day without interruption. The idea that "I drive home from work and then I'm mentally gone" is missing, and you have to force yourself to take a break. (Expert \#12)

At the organizational level, three interviewees said that companies have learned that their technical infrastructure can function well even in this extreme situation, and two noted the organizational benefits of increased efficiency in many teams as a result of virtual collaboration and more efficient allocation of working hours. Six participants referred to the economic benefits of fewer business trips and lower transfer times and costs, and three noted the associated contribution to climate and environmental protection. In addition, three suggested that this is a good opportunity for many organizations to rethink their processes and to reposition themselves for the future.

However, the participating experts also observed some negative effects of virtualization on work performance, especially with regard to collaboration and creativity.

I believe we still need face-to-face interaction. [...] It is not the case that everything [feelings, emotions, etc.] can now be represented digitally. There is a loss of quality. (Expert \#8)

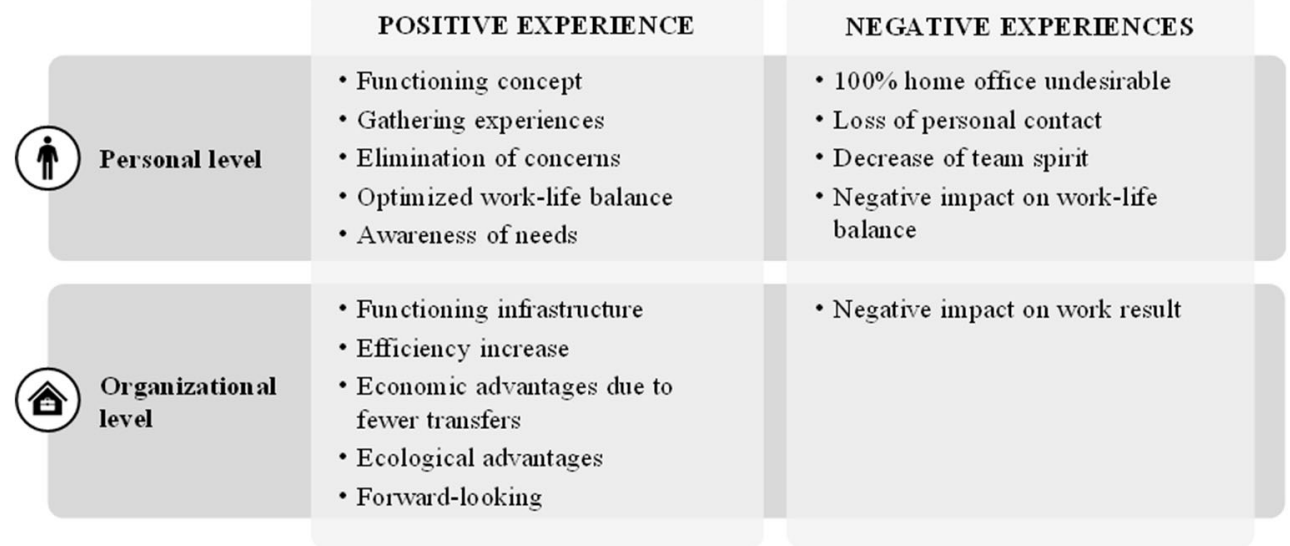

Figure 8. Positive and negative experiences of virtual working.

Adjusted conceptions of future work. Our findings also provide some indication of which traditional concepts of work might endure beyond the pandemic and which new concepts might persist. Figure 9 shows how concepts of work have changed over the course of 2020 and possible implications for the future of work.

All fifteen of the participating experts anticipate a hybrid model of future work combining office and home-based work. Seven interviewees noted that many employees can already configure their own working arrangements to some extent, including its location, depending on the task to be performed. Six agreed that creative workshops will return to the office once the pandemic has been contained, and four believed the same would apply to selected activities that require office infrastructure or special equipment.

I think [...] that employees will be more concerned in the future about the kinds of work to be performed in the office and what kinds of work might more usefully be completed from home. In other words, situated working [...] will become more important. (Expert \#14)

With regard to working hours, two interviewees expressed a wish to remain free to organize their own working day in the future.

And that's a good thing because I think it gives employees a lot of flexibility to decide for themselves how and during what hours they want to work. (Expert \#9)

The COVID-19 crisis has also highlighted the importance of information technologies for daily work, and five interviewees believed that proven tools and digital work methods established during the pandemic will continue to be useful, with an ongoing increase in the use of technology. Seven anticipated that collaboration will increasingly be virtualized, especially for those collaborating over greater distances. However, five interviewees said they would prefer to meet in person, primarily to build and strengthen team cohesion. By implication, it seems likely that employees will make conscious decisions about whether to meet virtually or physically. 


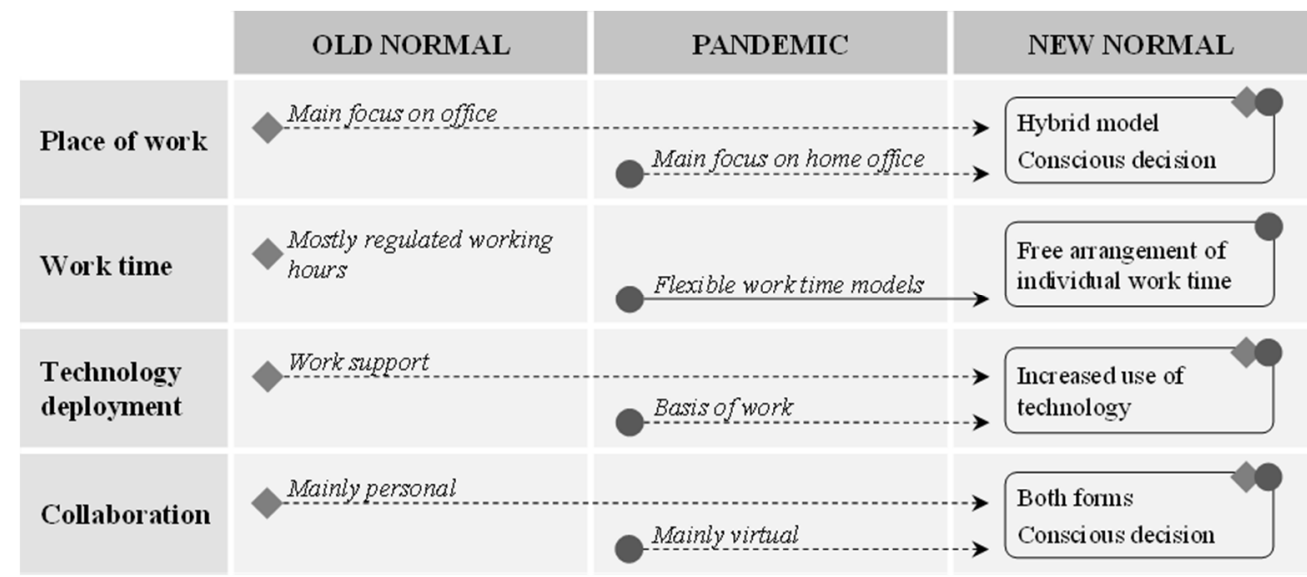

Figure 9. Changing concepts of work over time.

The future of work. Our findings indicate that the COVID-19 crisis has accelerated the move to New Work, as well as consolidating the megatrends of digital transformation and globalization. Figure 10 summarizes some key trends that will shape the future of work. All fifteen participating experts agreed that work must become flexible in terms of location and time. Eight referred to the development of work models that can be adapted to the individual needs of employees in order to enhance work-life balance. At the same time, increasing virtualization will enable organizations to hire employees regardless of place of residence or company location.

So, I believe that the work of the future will first and foremost be location- and time-independent because that simply aligns better with our flexible lifestyles, and that everyone will be able to make such decisions for themselves. (Expert \#13)

It can also be assumed that office-based places of work will remain necessary in the long term. However, according to eleven of the fifteen interviewees, the response to the current pandemic suggests that organizations will reduce their office space because of declining capacity utilization, and that office environments will have to be designed more flexibly in future.

I think this will tend to increase the proportion of employees working from home, which I think will prompt companies to reduce their office space to some extent. (Expert \#6)

In addition, seven interviewees believed that a change in corporate and work culture is inevitable, as organizations must become more structurally adaptable to react rapidly to change and find new ways of retaining employees regardless of location. Along with new ways of working and new forms of collaboration, other values are also becoming more important. For example, in-house training and further education will need to focus more on soft skills, as well as creativity, inclusion, and intrinsic motivation. The new challenges posed by virtual leadership will require a more transformational style that focuses on results.

In the future, people will need completely different skills [...] and values like creativity or originality. [...]

We need completely different skills. (Expert \#10)

Four participants also noted a need to optimize both office and network technical infrastructure structure to connect to home offices. Some organizations have already begun to equip employees to work from home, and our interviewees shared the view that expenditure on technical equipment will continue to increase.

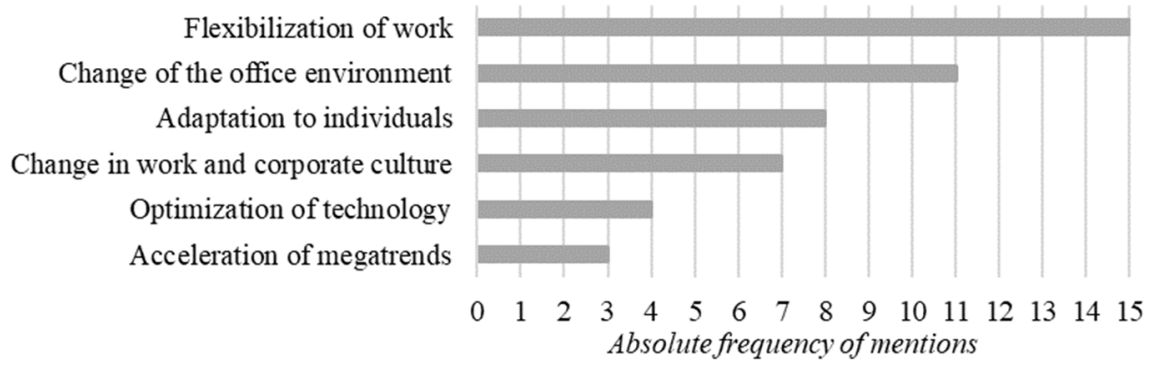

Figure 10. The future of work: Some key trends.

\section{Discussion}

This section reflects on the results of the analysis and relates the findings to previous research and the implications for future working practices. The main results of the study are summarized in Table 2.

Studies completed before the onset of the pandemic described how new office concepts, home-based working, flexible working, and virtual forms of collaboration will shape the future world of work (Blok et al., 2012; 
Hoendervanger, Van Yperen, Mobach, \& Albers, 2019; Pyöriä, 2011). The main finding of the present study is that the COVID-19 crisis has significantly accelerated the transition to new ways of working, and that these changes are already underway. Both the experts we interviewed and the latest scientific sources (Nediari et al., 2021; Savić, 2020; Umbs, 2020) have confirmed that organizations and employees rethought their PWEs, hours, and ways of working during the pandemic.

\subsection{Future work location and working time models}

The interview data indicate that, for many employees, the role of the office and home office has changed during the COVID-19 crisis. While the office was previously the epicenter of daily work, the pandemic has shifted the emphasis to the home office as described by Savić (2020), confirming that most individual activities can continue in this way, often with personal and organizational advantages. To that extent, the home office can be expected to retain its importance in the future as confirmed by the recent literature (Savić, 2020; Schmidtner et al., 2021; Umbs, 2020).

While offices will continue to play an important role, organizations are likely to reduce office space for capacity utilization and cost saving as confirmed by Parker (2020). On that basis, we formulated the following proposition.

Proposition 1a: During the pandemic, the focus of work has shifted from the office to the home office as another permanent workplace option.

At the same time, the importance of the office as a meeting place and venue for personal collaboration with colleagues became increasingly apparent during the pandemic. Our interviewees believed that this increased appreciation will endure, and that view is supported by several other studies (Parker, 2020; Samani \& Alavi, 2020). On that basis, we formulated the following proposition.

Proposition 1b: The office has gained in importance as a venue for personal encounters. Organizations are

likely to use the office more frequently and deliberately for this purpose in the future.

The future of work is also likely to involve a hybrid model combining office and home-based activities (Schmidtner et al., 2021). Our findings confirm that individual and focused work can be performed very well in the home office. At the same time, offices remain a great asset, especially for team and creative work, and are essential for activities that require special equipment. These trends are also described in Owen, Watson, and White (2020) and corroborate Blok et al.'s (2012) investigation of the purposes served by office buildings. Companies need to ensure that post-pandemic office design focuses on employee health by increasing workplace hygiene standards (see Nediari et al., 2021). In this context, it is reasonable to assume that employees will in the future decide where they perform which activities (Wessels et al., 2019). On that basis, we formulated the following proposition.

Proposition 2a: In future, employees will consciously choose a suitable work location according to activity type. While individual and focused activities may be performed in the home office, team and creative tasks are likely to be performed in the office. For that reason, planning and consultation involving teams and managers will be essential.

Our interview results suggest a need for different work zones within the office environment, allowing employees to switch flexibly. This will ensure that diverse activities during the working day can be matched to work locations that meet the employee's needs. This principle of activity-based working (Appel-Meulenbroek et al., 2011; Eismann et al., 2021) allows every employee to choose an appropriate workspace for the task in hand. As an optional work location, the home office expands these choices beyond the office as a decentralized form of activitybased working. On that basis, we formulated the following proposition.

Proposition 2b: Non-territorial office layouts in combination with ABW create the spatial conditions for work location planning based on employee and task requirements.

The increasing flexibilization of the working world means that knowledge work will become fully locationindependent. For example, mobile working will increasingly enable employees to decide where they want to work, perhaps performing part of their job in a café, park, or vacation home (Dumitraşcu-Băldău \& Dumitraşcu, 2017). Many organizations had already agreed group arrangements for mobile working before the pandemic, but these were used only in exceptional cases (Belzunegui-Eraso \& Erro-Garcés, 2020; Pyöriä, 2011). The present findings suggest that the COVID-19 crisis has prompted a rethink in this regard, and the home office option seems likely to be used more often in the future. In this context, the distance between company location and place of residence will become less important as a recruitment criterion for both organizations and employees as outlined in Nediari et al. (2021) and Thibault Landry, Schweyer, and Whillans (2017).

Our interview data and other recent studies also indicate that employees appreciate the flexible hours when working from home and would like this to continue (Diab-Bahman \& Al-Enzi, 2020). This increases the likelihood that organizations will introduce more flexible models of working time in the future (Davis et al., 2003; De Paoli et al., 2015; Naotunna \& Zhou, 2021). Our results also align with other evidence (Diab-Bahman \& Al-Enzi, 2020) that organizations can meet employees' individual needs, including work-life balance, by granting them flexibility in terms of time and location, and this is already a decisive factor when judging an employer's attractiveness (Stemmle \& Hampton, 2020). On that basis, we formulated the following proposition. 
Proposition 3: In the future, work will be flexible in terms of location and time and will adapt to the employee's individual needs and life situation in the absence of operational and team-related conflicts.

However, our results also show that a physical office is important for organizations because it gives employees an identity and facilitates physical contact between colleagues. Moreover, office premises are often needed for purposes such as meetings with partners and customers. More generally, organizations are already working on various office concepts that will enhance employee flexibility and attract new talent. In the future, for example, decentralized offices will mean that "the office comes to the employee" by being located within a short commute. In this way, working spaces and smaller hubs can be integrated with other locations (Beaudoin, Georgules \& Raicht, 2020; Parker, 2020). On that basis, we formulated the following proposition.

Proposition 4: In the fight to attract new talent, organizations will have to offer modern office solutions that are decentralized and close to their employees and potential employees.

\subsection{Future collaboration}

During the pandemic, teamworking has changed fundamentally in most organizations. Based on our interview results, these changes are likely to have long-term implications for collaboration.

As work has largely shifted to the home office, task-related communication and coordination have changed accordingly in most of the case organizations. In particular, as digital communication and collaboration tools become indispensable for daily work, processes have adapted accordingly. These changes seem more significant for communication than for coordination. Indeed, those who were already using digital tools and hybrid meeting formats in virtual teams barely noticed any change. Conversely, Green et al. (2020) and Wang, Liu, Qian, and Parker (2021) reported that less experience of working from home is associated with a greater sense of upheaval. On that basis, we formulated the following proposition.

Proposition 5a: The more experience workers had of virtual collaboration before the pandemic, the easier it was to relocate work to the home office.

In addition, our findings clearly indicate that virtual collaboration worked better for teams that already knew each other personally than for newly formed teams or virtual teams. On that basis, we formulated the following proposition.

Proposition 5b: Successful transition to virtual collaboration depends on team members' existing level of acquaintance. When integrating new colleagues or starting a new project, it is therefore important to bring virtual teams together physically to build personal and team relations.

During the pandemic, it became clear that virtual collaboration from the home office works well, especially for shorter meetings and coordination activities. In general, virtual activities and the more frequent participation of distant colleagues enhance team cooperation, openness, friendliness, tolerance, and punctuality. Additionally, professional exchanges tend to be more focused, and the scheduled time is used more effectively, which also contributes to greater efficiency. The evidence to date suggests that organizations will continue to use established communication and collaboration tools to sustain the benefits of virtual collaboration as discussed in the existing literature (Kaushik \& Guleria, 2020; Liu et al., 2020; Sharfuddin, 2020). On that basis, we formulated the following proposition.

Proposition 6a: In coordination meetings, virtual working methods offer communicative, organizational, and economic advantages. To exploit this potential, departments and teams must agree on standards for conducting virtual meetings.

In contrast, virtual collaboration can undermine non-verbal communication and increase the risk of misunderstandings and conflicts in more complex and substantive meetings (Rutkowski, Vogel, Van Genuchten, Bemelmans, \& Favier, 2002; Schulze \& Krumm, 2017). While this problem can be mitigated by the use of webcams, especially in smaller meetings (Brodsky, 2020), this cannot entirely replace face-to-face interaction. Our own data and the relevant literature confirm that employees miss personal contact and informal communication with their colleagues, with adverse effects on team cohesion (Van der Lippe \& Lippényi, 2020). For that reason, teams should continue to meet regularly in the office for team meetings and corporate events. In line with Oshri, Kotlarsky, and Willcocks's (2020) findings, we formulated the following proposition.

Proposition 6b: Face-to-face meetings with team members are an important means of strengthening team spirit and relationships and integrating new team members. Managers and employees share the responsibility for organizing such meetings and ensuring their success.

Collaboration is increasingly likely to be virtualized, especially over greater spatial distances or when a business trip or change of location seems disproportionate in terms of meeting duration. The savings on employee time and travel costs will also contribute indirectly to environmental protection as highlighted in the recent scientific literature (Diab-Bahman \& Al-Enzi, 2020; Jordan \& Palmer, 2020; Nediari et al., 2021). On that basis, we formulated the following proposition.

Proposition 7a: Organizations must adapt their travel policies to ensure that, wherever possible, cross-site or external collaboration is replaced by virtual collaboration, so contributing to cost reduction and increased 
efficiency and sustainability.

If future collaboration is to successfully combine virtual meetings, digital communication, and face-to-face encounters, organizations and teams must develop common standards and values for this hybrid work environment and a format for communication and collaboration that is appropriate to the given situation.

Proposition 7b: Organizations must promote a new culture of collaboration and combine synergies by developing appropriate rules and creating conditions that support complementary face-to-face and virtual forms of work.

New virtual forms of collaboration and joint working methods also increase the importance of digital and social skills and mutual trust. Our own data and other recent studies confirm that employees will increasingly need strong digital and social skills as well as openness, initiative, and personal responsibility for successful collaboration (Schulze et al., 2017; Van Laar et al., 2020). Managers must develop a more transformational and results-oriented style of leadership that places greater trust in their employees and supports them in self-organizing (Eismann et al., 2021). This need for appropriate support and training is also highlighted in the existing academic literature (Feitosa \& Salas, 2020; Tokarchuk, Gabriele, \& Neglia, 2021). On that basis, we formulated the following proposition.

Proposition 8: Education systems and organizations must equip employees and managers with the necessary skills and abilities to engage in new forms of collaboration. In addition, organizations should create career concepts, target agreements, and targeted incentives for professional development and skills use to enhance employees' intrinsic motivation.

\subsection{Future creativity work}

Our interview data confirm the strong impact on creativity of work virtualization and changes in work location and hours. In particular, the PWE is considered important for creative work in terms of access to different workspaces and formal and informal exchanges with colleagues. New ways of working can be said to have both positive and negative effects on individual creativity. In line with Waizenegger et al. (2020), our findings show, for example, that isolated home office work can cause alienation from one's own team, loss of mutual spontaneous inspiration, and lack of regular feedback. On the other hand, being able to work partly from home and the associated flexibility in terms of time can promote individual creativity (Naotunna \& Zhou, 2021; Vega, Anderson, \& Kaplan, 2015)

Echoing the findings of Naotunna and Zhou (2021) and Vega et al. (2015), our interviewees noted that the home office offers a quiet atmosphere for intensive work on ideas and strategic problems. Furthermore, employees are likely to feel comfortable and creative in a self-designed environment that stimulates free thinking. On that basis, we formulated the following proposition.

Proposition 9a: The feeling of freedom engendered by the home office work environment can enhance individual creative work.

Relocating to the home office also grants employees the freedom to schedule their working hours more flexibly, and being able to adapt the working day to one's own needs is a form of autonomy that can also encourage creative moments (see Diab-Bahman \& Al-Enzi, 2020). In addition, employees are more likely to take creativity-enhancing breaks at home, which also improves their work-life balance. On that basis, we formulated the following proposition.

Proposition 9b: The COVID-19 crisis has accelerated the introduction of flexible working time models, freeing employees to organize their own working day and to better exploit their creative potential.

Whether and to what extent creativity is enhanced by home-based working depends however on the more general domestic situation. For example, the lack of a suitable home workspace or regular disruption by family members or roommates is likely to interrupt creative thinking (Lopez-Persem, Bieth, Guiet, Ovando-Tellez, \& Volle, 2021). In addition, difficulties in reconciling work and personal life may inhibit creativity, so increasing work intensity and stress levels. According to Russell, O'Connell, and McGinnity (2009), these issues frequently arise when working from home. On that basis, we formulated the following proposition

Proposition 9c: In the future, employees will have to self-organize and decide for themselves whether the home office is suitable for creative individual work according to individual and task requirements and needs. In contrast to individual creative work, we found no evidence that these altered working methods have any positive effects on team creative work. In particular, the advantages of virtual collaboration, such as increased openness and efficiency, do not apply to team creativity, which seems to be undermined by this approach. Specifically, the adverse effects of physical distance on group dynamics and spontaneous encounters inhibits the flow that underpins creative processes and generates creative ideas (Allen, Golden, \& Shockley, 2015; Kniffin et al., 2021). Moreover, when compared to analog and haptic working methods, digital tools often impede team creative work, as virtualization leads to a lack of activity and direct interaction.

Our interviewees emphasized that the quality of virtual creative work processes and outcomes also depend heavily on the hardware and software used. While an increasing number of technologies provide good support for 
virtual creative collaboration, organizations are not always familiar with the right software. On that basis, we formulated the following proposition.

Proposition 10: Given the current state of the art, successful team creative work still depends on personal exchange, a shared physical environment with creative work tools, and haptic interaction. It follows that team creative work should in future be located principally at the company's offices.

In the longer term, many organizations continue to seek out suitable digital tools to improve the quality of virtual creative work (Schmidtner et al., 2021). Looking beyond the pandemic, virtual workshops based on such tools should aim to improve participant activity and interaction for better distance collaboration. Many emerging collaboration tools (e.g., whiteboards, concept boards, voting and polling tools) support creative and team-oriented work by encouraging active participation and creative forms of interaction. In addition, many employees now own laptops or tablets with touchscreens, which can be used for quick scribbles and visualizations in much the same way as haptic work. Smartphone apps for virtual meetings further expand the "walk-and-talk" work mode to the home office, and organizations must continue to work on solutions of this kind to make virtual creative collaboration more effective. In addition, effective moderation can enhance interaction in virtual meetings by actively involving all team members and encouraging everyone to express their ideas. In particular, it is important to allow for informal conversations at the outset to promote an atmosphere of trust that encourages spontaneous exchanges and so enriches creative work (Newman \& Ford, 2021; Schmidt, 2014). Trust within a team also requires a culture of constructive criticism as a prerequisite for interactive collaboration and the lively exchange of ideas (Ford, Piccolo, \& Ford, 2017). On that basis, we formulated the following proposition.

Proposition 11: Appropriate creative tools, effective moderation, and a trust-based and open team culture will promote the activity and interaction needed for creative work.

As creativity is already seen as one of the most important competencies for future work (Amabile, 1998; Van Laar et al., 2020), it is important to encourage ongoing creative thinking, supported by relevant training. On that basis, we formulated the following proposition.

Proposition 12: In the working world of the future, creativity will be a key employee qualification and a critical success factor for organizations. Building on foundations laid in early childhood and education, selective recruiting and appropriate training programs will enable companies to create the requisite cultural conditions to encourage creativity.

Table 2. Key findings

\begin{tabular}{|c|c|c|}
\hline Field & \multicolumn{2}{|c|}{ Proposition } \\
\hline \multirow{6}{*}{ 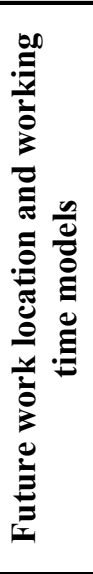 } & & $\begin{array}{l}\text { During the pandemic, the focus of work has shifted from the office to the home office as another } \\
\text { permanent workplace option. }\end{array}$ \\
\hline & $1 b:$ & $\begin{array}{l}\text { The office has gained in importance as a venue for personal encounters. Organizations are likely } \\
\text { to use the office more frequently and deliberately for this purpose in the future. }\end{array}$ \\
\hline & $2 a:$ & $\begin{array}{l}\text { In future, employees will consciously choose a suitable work location according to activity type. } \\
\text { While individual and focused activities may be performed in the home office, team and creative } \\
\text { tasks are likely to be performed in the office. For that reason, planning and consultation } \\
\text { involving teams and managers will be essential. }\end{array}$ \\
\hline & $2 b$ & $\begin{array}{l}\text { Non-territorial office layouts in combination with ABW create the spatial conditions for work } \\
\text { location planning based on employee and task requirements. }\end{array}$ \\
\hline & & $\begin{array}{l}\text { In the future, work will be flexible in terms of location and time and will adapt to the employee's } \\
\text { individual needs and life situation in the absence of operational and team-related conflicts. }\end{array}$ \\
\hline & 4: & $\begin{array}{l}\text { In the fight to attract new talent, organizations will have to offer modern office solutions that } \\
\text { are decentralized and close to their employees and potential employees. }\end{array}$ \\
\hline \multirow{5}{*}{ 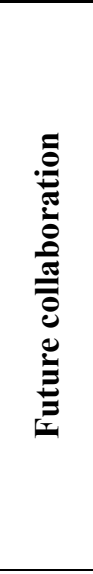 } & & $\begin{array}{l}\text { The more experience workers had of virtual collaboration before the pandemic, the easier it was } \\
\text { to relocate work to the home office. }\end{array}$ \\
\hline & & $\begin{array}{l}\text { Successful transition to virtual collaboration depends on team members' existing level of } \\
\text { acquaintance. When integrating new colleagues or starting a new project, it is therefore } \\
\text { important to bring virtual teams together physically to build personal and team relations. }\end{array}$ \\
\hline & $6 a:$ & $\begin{array}{l}\text { In coordination meetings, virtual working methods offer communicative, organizational, and } \\
\text { economic advantages. To exploit this potential, departments and teams must agree on standards } \\
\text { for conducting virtual meetings. }\end{array}$ \\
\hline & $6 b:$ & $\begin{array}{l}\text { Face-to-face meetings with team members are an important means of strengthening team spirit } \\
\text { and relationships and integrating new team members. Managers and employees share the } \\
\text { responsibility for organizing such meetings and ensuring their success. }\end{array}$ \\
\hline & & $\begin{array}{l}\text { Organizations must adapt their travel policies to ensure that, wherever possible, cross-site or } \\
\text { external collaboration is replaced by virtual collaboration, so contributing to cost reduction and } \\
\text { increased efficiency and sustainability. }\end{array}$ \\
\hline
\end{tabular}




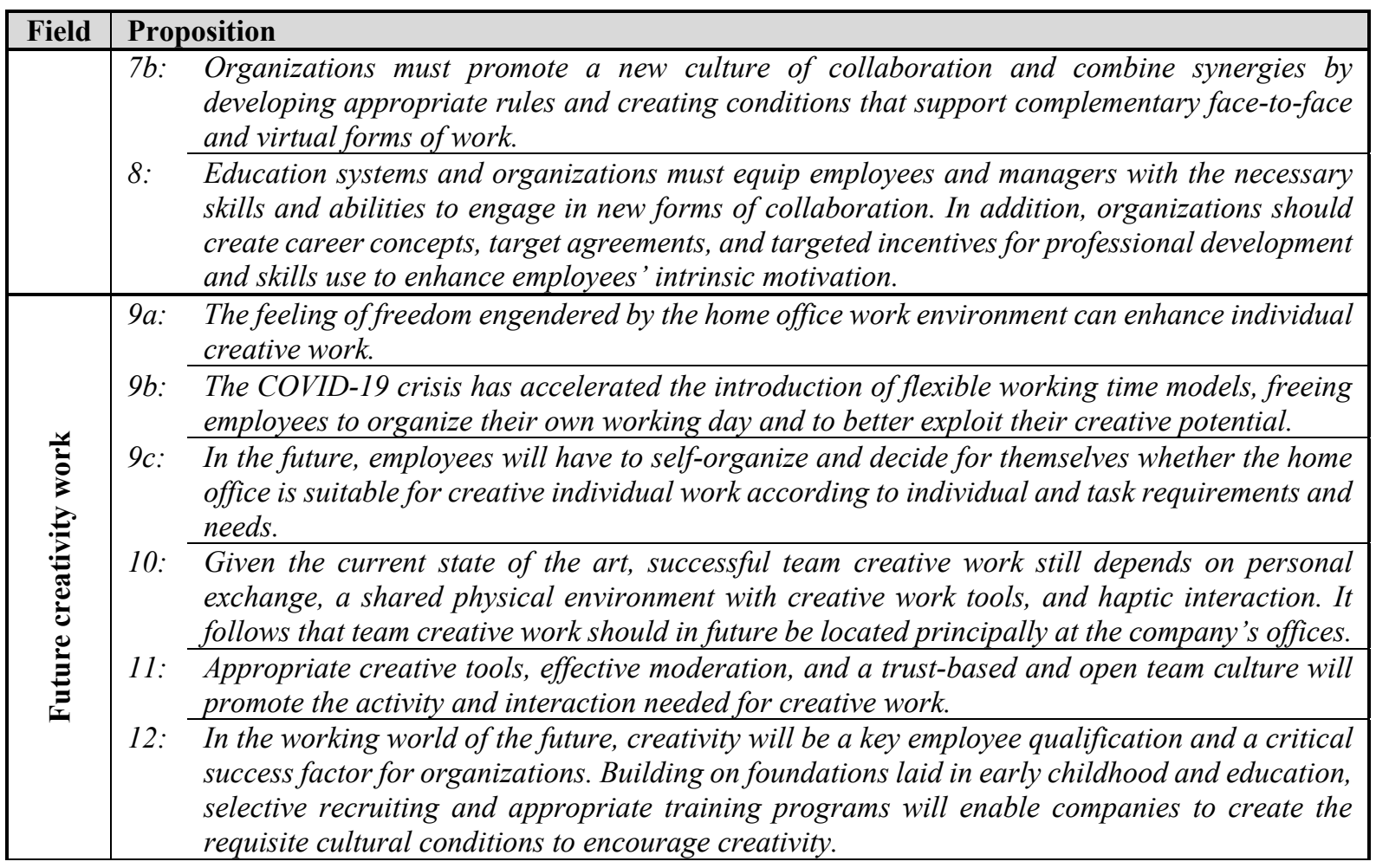

\section{Implications and limitations of the study}

\subsection{Implications}

The present study deepens existing knowledge about the impact of the COVID-19 crisis on work practices in industrial companies. In particular, it contributes to the literature on the transformative role of PWEs and the future importance of differentiated workspaces. Our findings also clarify the pandemic's effects on collaboration and future work practices, as well as the impact of changing work conditions on creative work. Our findings also highlight the role of the COVID-19 crisis as a catalyst for virtualization and the accelerated transformation of organizations by digitalization and New Work. To ensure the transfer of these positive effects to the post-pandemic world of work, we make the following recommendations.

Office spaces designed for teamwork and creativity in combination with a well-equipped home office environment for individual and intensive work will more fully meet employees' needs, creating the conditions for enhanced productivity. As many employees will more often work from home in the future, organizations must seek to reconfigure and reduce existing office space. To fully exploit the benefits of these new arrangements, occupancy planning for team workspaces must be transparent and flexible, taking account of both short-term situational requirements and long-term capacity requirements.

During the COVID-19 crisis, it became clear that certain forms of team collaboration and enhanced productivity can be sustained in the longer term. With ongoing improvement of tools and methods for virtual creative work, team members will be able to work together regardless of location, enabling organizations to recruit specialized talent from anywhere. To succeed in the long term in this hybrid world of work, organizations will need appropriate management tools and must continue to develop employees' skills and ability to adapt to virtual work.

Remote working also requires managers and employees to develop a culture of trust. By establishing an error culture, this can create the conditions for innovative, constructive, and creative work. In hybrid and virtual teams, reduced personal contact means that motivation, team spirit, and employee loyalty can suffer. However, compensatory measures like virtual team events, joint virtual coffee breaks, and targeted physical meetings can assist team building by developing and intensifying interpersonal relationships.

Organizations should also develop extensive regulations for mobile working and use of the home office as a regular workplace. Along with rules governing working time, location, and insurance, company agreements should address the ongoing development of work practices and performance evaluation.

\subsection{Limitations and further research}

Given the exploratory nature of this qualitative study, it inevitably has some limitations. First, individual results must be viewed with caution, as the sample was relatively small and the results apply only under specific conditions. 
As almost all of the interviewees were experts from German companies, the results take no account of national, cultural, or organizational differences, which should be explored in future studies. In general, the study's content limits the generality of these results. For example, as multiple economic, organizational, technological, and social factors contribute to the current situation, each individual assesses the effects of the crisis in light of their own life situation and personal needs. To that extent, the interview data reflect only the subjective views of the individuals in question. As the pandemic is ongoing, the ultimate consequences for work in the future remain somewhat unpredictable. Most companies are currently undergoing an accelerated process of transformation, and the effects of many measures are only now becoming clear. For that reason, the experts' statements refer only to the immediate present, and any assumptions about the "New Normal" and the future of work must be tested again at a later date.

To assess the study's validity and significance, future studies should recruit larger samples. The number of interviews should be increased, and international companies from different industries should be included to explore the new work practices from other perspectives and cultural backgrounds.

Future studies must also examine the requirements for post-COVID-19 office design in order to comply with hygiene standards and give employees a feeling of security. Although Nediari et al. (2021) provide the first theoretical approaches to office design, corresponding designs and processes have to be tested and adapted on a company-specific basis, which is why best practices and experiences should be documented.

Another topic of interest is the change in models of cooperation and management in the wake of the pandemic and how these can be sustained at the level of corporate culture. The present findings suggest that only those companies that can further develop their corporate culture and value system can successfully adapt to a New Normal. Against this background, further studies must analyze these future requirements in order to create appropriate mechanisms and trainings preparing employees and managers alike.

Finally, future studies should also incorporate quantitative measures of virtual collaboration effects on productivity and creative work, as certain work processes must first be established. In particular, the pandemic has shown that companies and employees alike are able to come up with creative solutions to shape current change and maintain productivity. The pandemic is, however, an exceptional situation, which is why future studies should investigate how productivity and creativity in the New Normal and in a hybrid working world can be supported in an employee-friendly manner.

\section{References}

Allen, T. D., Golden, T. D., \& Shockley, K. M. (2015). How effective is telecommuting? Assessing the status of our scientific findings. Psychological Science in the Public Interest, 16(2), 40-68.

Amabile, T. M. (1988). A model of creativity and innovation in organizations. Research in Organizational Behavior, 10(1), 123-167.

Appel-Meulenbroek, R., Groenen, P., \& Janssen, I. (2011). An end-user's perspective on activity-based office concepts. Journal of Corporate Real Estate, 13(2), 122-135.

Avolio, B. J., Walumbwa, F. O., \& Weber, T. J. (2009). Leadership: Current theories, research, and future directions. Annual Review of Psychology, 60, 421-449.

Babapour, M., Karlsson, M. A. \& Osvalder, A.-L. (2018). Appropriation of an activity-based flexible office in daily work. Nordic Journal of Working Life Studies, 8(S3), 71-94.

Bailey, N. B. K. D. E., \& Kurland, N. B. (1999). The advantages and challenges of working here, there, anywhere, and anytime. Organizational dynamics, 28(2), 53-68.

Baruch, Y. (2001). The status of research on teleworking and an agenda for future research. International Journal of Management Reviews, 3(2), 113-129.

Beaudoin, C., Georgules, J., \& Raicht, T. (2020). Tenant needs in a post pandemic world. (2020 Forecast Series No. 4). Chicago: JLL.

Belzunegui-Eraso, A., \& Erro-Garcés, A. (2020). Teleworking in the context of the Covid-19 crisis. Sustainability, 12(9), 3662.

Blok, M. M., Groenesteijn, L., Schelvis, R., \& Vink, P. (2012). New ways of working: Does flexibility in time and location of work change work behavior and affect business outcomes? Work, 41(1), 2605-2610.

Bødker, S., \& Sundblad, Y. (2008). Usability and interaction design-New challenges for the Scandinavian tradition. Behaviour \& Information Technology, 27(4), 293-300.

Brinkmann, S., \& Kvale, S. (2018). Doing interviews. Los Angeles, London: Sage.

Brodsky, A. (2020). Virtual surface acting in workplace interactions: Choosing the best technology to fit the task. Journal of Applied Psychology.

Busse, R., \& Weidner, G. (2020). A qualitative investigation on combined effects of distant leadership, organisational agility and digital collaboration on perceived employee engagement. Leadership \& Organization Development Journal, 41(4), 535-550.

Castellani, D., Hameed, B. Z., Tanidir, Y., Naik, N., Teoh, J. Y.-C., Shah, M., Langer Wroclawski, M., Budnar Kunjinettu, A., Ibrahim, S., Donalisio da Silva, R., Rai, B., de la Rosette, J.J.M.C.H., Tp, R., Gauhar, V., \& 
Somani, B. (2020). Online, face to face and hybrid meetings. What is the new normal in the COVID-19 era? A global collaborative survey by iTRUE group and UroSoMe working group. Research Square, 1.

Colbert, A., Yee, N., \& George, G. (2016). The digital workforce and the workplace of the future. Academy of Management Journal, 59(3), 731-739.

Davidson, L. (2020), New ways of working: Becoming more flexible out of lockdown. [Online] Available: https://www.recruiter.co.uk/opinion/2020/07/viewpoint-new-ways-working.

Davis, D. D., \& Bryant, J. L. (2003). Influence at a distance: Leadership in global virtual teams. Advances in Global Leadership, 3(1), 303-340.

de Kok, A. (2016). The new way of working: Bricks, bytes, and behavior. In J. Lee (Ed.), The impact of ICT on work (pp. 9-40). Singapore: Springer.

de Leede, J., \& Nijland, J. (2016). Understanding teamwork behaviors in the use of new ways of working. In J. de Leede (Ed.), Advanced series in management. New ways of working practices (pp. 73-94). Emerald Group Publishing.

De Paoli, D., \& Ropo, A. (2015). Open plan offices - the response to leadership challenges of virtual project work? Journal of Corporate Real Estate, 17(1), 63-74.

Diab-Bahman, R. \& Al-Enzi, A. (2020). The impact of COVID-19 pandemic on conventional work settings. International Journal of Sociology and Social Policy, 50(9/10), 909-927.

Dumitraşcu-Băldău, I., \& Dumitraşcu, D. D. (2017). Skills and competences international project managers need in order to be successful in a virtual work environment. Bulletin of the Transilvania University of Brasov. Economic Sciences, Series V, 10(2), 63-70.

Edmondson, A. C., \& McManus, S. E. (2007). Methodological fit in management field research. Academy of Management Review, 32(4), 1246-1264.

Eisenhardt, K. M. (1989). Building theories from case study research. Academy of Management Review, 14(4), $532-550$.

Eisenhardt, K. M., \& Graebner, M. E. (2007). Theory building from cases: Opportunities and challenges. Academy of Management Journal, 50(1), 25-32.

Eismann, T. T., Pakos, O., Rücker, M., Meinel, M., Maier, L., \& Voigt, K. I. (2021). Understanding the Mechanisms of Activity-based Workspaces: A Case Study. Environment and Behavior, 00139165211008240.

Elsbach, K. D., \& Bechky, B. A. (2007). It's more than a desk: Working smarter through leveraged office design. California Management Review, 49(2), 80-101.

Feitosa, J., \& Salas, E. (2020). Today's virtual teams: Adapting lessons learned to the pandemic context. Organizational Dynamics, 50(1), 100777.

Ford, R. C., Piccolo, R. F., \& Ford, L. R. (2017). Strategies for building effective virtual teams: Trust is key. Business Horizons, 60(1), 25-34.

Gale, H. F. Jr., Wojan, T. R., \& Olmsted, J. C. (2002). Skills, flexible manufacturing technology, and work organization. Industrial Relations: A Journal of Economy and Society, 41(1), 48-79.

Gerards, R., de Grip, A., \& Baudewijns, C., (2018). Do new ways of working increase work engagement? Personnel Review, 47(2), 517-534.

Gerdenitsch, C., Korunka, C., \& Hertel, G. (2018). Need-supply fit in an activity-based flexible office: A longitudinal study during relocation. Environment and Behavior, 50(3), 273-297.

Gioia, D. A., Corley, K. G. \& Hamilton, A. L. (2013). Seeking qualitative rigor in inductive research. Organizational Research Methods, 16(1), 15-31.

Gläser, J., \& Laudel, G. (2010). Experteninterviews und qualitative Inhaltsanalyse: als Instrumente rekonstruierender Untersuchungen (4th ed.). Wiesbaden: VS Verlag.

Gray, M., Hudson, N., \& Gordon, G. (1996). Teleworking explained. Long Range Planning, 29(6), 910-910.

Green, N., Tappin, D., \& Bentley, T. (2020). Working from home before, during and after the Covid-19 pandemic: Implications for workers and organisations. New Zealand Journal of Employment Relations, 45(2), 5-16.

Haapakangas, A., Hallman, D. M., Mathiassen, S. E., \& Jahncke, H. (2018). Self-rated productivity and employee well-being in activity-based offices: The role of environmental perceptions and workspace use. Building and Environment, 145, 115-124.

Haapakangas, A., Hallman, D. M., Mathiassen, S. E., \& Jahncke, H. (2019). The effects of moving into an activitybased office on communication, social relations and work demands-A controlled intervention with repeated follow-up. Journal of Environmental Psychology, 66, 101341.

Halford, S. (2005). Hybrid workspace: Re-spatialisations of work, organisation and management. New Technology, Work and Employment, 20(1), 19-33.

Härenstam, A. (2005). Different development trends in working life and increasing occupational stress require new work environment strategies. Work, 24(3), 261-277.

Harteis, C. (2018). Machines, change and work: An educational view on the digitalization of work. In Harteis, C. (Ed.), Professional and practice-based learning. The impact of digitalization in the workplace (pp. 1-10). 
Cham: Springer International Publishing.

Hildebrandt, J., Kluge, J., \& Ziefle, M. (2020). A successful transformation of work? An exploratory analysis on requirements and evaluation criteria. In M. Kurosu (Ed.), Human-computer interaction. Design and user experience (pp. 257-272). Cham: Springer International Publishing.

Hoendervanger, J. G., Van Yperen, N. W., Mobach, M. P., \& Albers, C. J. (2019). Perceived fit in activity-based work environments and its impact on satisfaction and performance. Journal of Environmental Psychology, $65,101339$.

Holsti, O. R. (1968). Content analysis. In G. Lindzey \& E. Aronson (Eds.), The handbook of social psychology (2nd ed.) (pp. 596-692). New York: McGraw-Hill.

Jensen, T. B. (2018). Digital transformation of work. Scandinavian Journal of Information Systems, 30(2), 27-40.

Johansson, J., Abrahamsson, L., Kåreborn, B. B., Fältholm, Y., Grane, C., \& Wykowska, A. (2017). Work and organization in a digital industrial context. Management Revue, 28(3), 281-297.

Jordan, C. J. \& Palmer, A. A. (2020). Virtual meetings: A critical step to address climate change. Science Advances, $6(38), 1-2$.

Kaushik, M., \& Guleria, N. (2020). The impact of pandemic COVID-19 in workplace. European Journal of Business and Management, 12(15), 1-10.

Kegel, P. (2017). The impact of the physical work environment of organizational outcomes: A structured review of the literature. Journal of Facility Management Education and Research, 1(1), 19-29.

Kim, J., Candido, C., Thomas, L., \& de Dear, R. (2016). Desk ownership in the workplace: The effect of nonterritorial working on employee workplace satisfaction, perceived productivity and health. Building and Environment, 103, 203-214.

Kniffin, K. M., Narayanan, J., Anseel, F., Antonakis, J., Ashford, S. P., Bakker, A. B., \& Vugt, M. V. (2021). COVID-19 and the workplace: Implications, issues, and insights for future research and action. American Psychologist, 76(1), 63.

Koclowski, M. D. (2010). Shared leadership: Is it time for a change?. Emerging Leadership Journeys, 3(1), $22-$ 32.

Kötting, D. (2019). Die Digitalisierung der Arbeit. Wirtschaftsinformatik \& Management, 11(5), 276-288.

Kvale, S. (1996). InterViews: An introduction to qualitative research interviewing. Thousand Oaks, London, New Delhi: Sage.

Leclercq-Vandelannoitte, A., \& Isaac, H. (2016). The new office: How coworking changes the work concept. Journal of Business Strategy, 37(6), 3-9.

Liu, Z., Van Egdom, D., Flin, R., Spitzmueller, C., Adepoju, O., \& Krishnamoorti, R. (2020). I don’t want to go back: Examining the return to physical workspaces during COVID-19. Journal of Occupational and Environmental Medicine, 62(11), 953-958.

Lopez-Persem, A., Bieth, T., Guiet, S., Ovando-Tellez, M., \& Volle, E. (2021). Through thick and thin: changes in creativity during the first lockdown of the Covid-19 pandemic. PsyArXiv, 1-37.

Madsen, S. R. (2003). The effects of home-based teleworking on work-family conflict. Human Resource Development Quarterly, 14(1), 35-58.

Magnusson, E., \& Marecek, J. (2015). Doing interview-based qualitative research. Cambridge: Cambridge University Press.

Manca, C., Grijalvo, M., Palacios, M., \& Kaulio, M. (2018). Collaborative workplaces for innovation in service companies: Barriers and enablers for supporting new ways of working. Service Business, 12(3), 525-550.

Maravelias, C. (2009). Health promotion and flexibility: Extending and obscuring power in organizations. British Journal of Management, 20, 194-203.

Maxwell, J. A. (2013). Qualitative research design: An interactive approach (3rd ed.). Thousand Oaks: Sage.

Mayring, P. (2016). Einführung in die qualitative Sozialforschung (6th ed.). Weinheim, Basel: Beltz.

Meinel, M., Maier, L., Wagner, T., \& Voigt, K. I. (2017). Designing creativity-enhancing workspaces: A critical look at empirical evidence. Journal of Technology and Innovation Management, 1(1), 1-12.

Miles, M., Huberman, M., \& Saldaña, J. (2020). Qualitative data analysis: A methods source-book (4th ed.). Thousand Oaks: Sage.

Misoch, S. (2019). Qualitative interviews. (2nd ed.). Berlin, Boston: De Gruyter.

Millward, L. J., Haslam, S. A., \& Postmes, T. (2007). Putting employees in their place: The impact of hot desking on organizational and team identification. Organization Science, 18(4), 547-559.

Mohammad, K., (2009). E-leadership: The emerging new leadership for the virtual organization. International Journal of Managerial Sciences, 3(1), 1-21.

Moll, F., \& de Leede, J. (2016). Fostering innovation: The influence of new ways of working on innovative work behavior. In J. de Leede (Ed.), Advanced series in management. New ways of working practices (pp. 95-143). Emerald Group Publishing.

Naotunna, N. P. G. S. I., \& Zhou, E. (2021). Telework and Creativity of Professional Employees: The Mediating 
Roles of Autonomy and Time Pressure. Journal of Creativity and Business Innovation, 7, 62-73.

Nediari, A., Roesli, C., \& Simanjuntak, P. M. (2021). Preparing post Covid-19 pandemic office design as the new concept of sustainability design. In IOP Conference Series, Earth and Environmental Science, 729(1), 012095 IOP Publishing.

Newman, S. A., \& Ford, R. C. (2021). Five Steps to Leading Your Team in the Virtual COVID-19 Workplace. Organizational Dynamics, 50(1), 1-11.

Oberländer, M., Beinicke, A., \& Bipp, T. (2020). Digital competencies: A review of the literature and applications in the workplace. Computers \& Education, 146, 103752.

Ollo-López, A., Bayo-Moriones, A., \& Larraza-Kintana, M. (2011). The impact of country-level factors on the use of new work practices. Journal of World Business, 46(3), 394-403.

O'Reilly, C. A. III, \& Tushman, M. L. (2013). Organizational ambidexterity: Past, present, and future. Academy of Management Perspectives, 27(4), 324-338.

Oshri, I., Kotlarsky, J., \& Willcocks, L. P. (2007). Global software development: Exploring socialization and faceto-face meetings in distributed strategic projects. The Journal of Strategic Information Systems, 16(1), 2549.

Owen, A., Watson, B., \& White, J. (2020). Rethinking smart workplaces in uncertain times: A human-centered approach to physical workspace planning is critical for short-term recovery and the long-term future of work. People \& Strategy, 43(3), 36-41.

Parker, L. D. (2020). The COVID-19 office in transition: Cost, efficiency and the social responsibility business case. Accounting, Auditing \& Accountability Journal, 33(8), 1943-1967.

Parviainen, P., Tihinen, M., Kääriäinen, J., \& Teppola, S. (2017). Tackling the digitalization challenge: How to benefit from digitalization in practice. International Journal of Information Systems and Project Management, 5(1), 63-77.

Pérez, M. P., Sánchez, A. M., \& de Luis Carnicer, M. P. (2002). Benefits and barriers of telework: Perception differences of human resources managers according to company's operations strategy. Technovation, 22(12), $775-783$.

Pyöriä, P. (2011). Managing telework: Risks, fears and rules. Management Research Review, 34(4), 386-399.

Ross, P. K., Ressia, S., \& Sander, E. J. (2017). Work in the 21st Century: How do I log on?. Bingley: Emerald Publishing.

Russell, H., O'Connell, P. J., \& McGinnity, F. (2009). The impact of flexible working arrangements on work-life conflict and work pressure in Ireland. Gender, Work \& Organization, 16(1), 73-97.

Rutkowski, A. F., Vogel, D. R., Van Genuchten, M., Bemelmans, T. M., \& Favier, M. (2002). E-collaboration: The reality of virtuality. IEEE Transactions on Professional Communication, 45(4), 219-230.

Saatçi, B., Akyüz, K., Rintel, S., \& Klokmose, C. N. (2020). (Re)Configuring hybrid meetings: Moving from usercentered design to meeting-centered design. Computer Supported Cooperative Work (CSCW), 29(6), 769794.

Samani, S. A., \& Alavi, S. M. S. Z. (2020). Are open-plan office designs still popular after coronavirus pandemic? Performance Improvement, 59(8), 24-32.

Savić, D. (2020). COVID-19 and work from home: Digital transformation of the workforce. The Grey Journal, 16(2), 101-104.

Schmidt, G. B. (2014). Virtual leadership: An important leadership context. Industrial and Organizational Psychology, 7(2), 182-187.

Schmidtner, M., Doering, C., \& Timinger, H. (2021). Agile Working during COVID-19 Pandemic. IEEE Engineering Management Review.

Schulze, J., \& Krumm, S. (2017). The "virtual team player": A review and initial model of knowledge, skills, abilities, and other characteristics for virtual collaboration. Organization-al Psychology Review, 7(1), 66-95.

Schwarzmüller, T., Brosi, P., Duman, D., \& Welpe, I. M. (2018). How does the digital transformation affect organizations? Key themes of change in work design and leadership. Management Revue, 29(2), 114-138.

Senge, P. M. (1990). The leader's new work: Building learning organizations. Sloan Management Review, 32(1), $7-23$.

Sharfuddin, S. (2020). The world after Covid-19. The Round Table, 109(3), 247-257.

Stahl, U. (2019). New Work und das neue WIR. Wirtschaftsinformatik \& Management, 11(5), 296-303.

Stalk, G. Jr., \& Hout, T. M. (1990). Competing against time. Research-Technology Management, 33(2), 19-24.

Stemmle, J., \& Hampton, D. G. (2020). Post COVID-19 employee benefits: What to look for in your compensation package. Journal of Financial Planning, 33(10), 23-25.

Stoepfgeshoff, S. (2018). The future of work: Work for the future. ISM Journal of International Business, 2(2), $26-28$.

Stokes, D., \& Bergin, R. (2006). Methodology or "methodolatry"? An evaluation of focus groups and depth interviews. Qualitative Market Research: An International Journal, 9(1), 26-37. 
Thibault Landry, A., Schweyer, A., \& Whillans, A. (2017). Winning the war for talent: Modern motivational methods for attracting and retaining employees. Compensation \& Benefits Review, 49(4), 230-246.

Tokarchuk, O., Gabriele, R., \& Neglia, G. (2021). Teleworking during the Covid-19 Crisis in Italy: Evidence and Tentative Interpretations. Sustainability, 13(4), 1-11.

Tschannen-Moran, M., \& Hoy, W. K. (2000). A multidisciplinary analysis of the nature, meaning, and measurement of trust. Review of Educational Research, 70(4), 547-593.

Umbs, C. (2020). Arbeiten nach Corona: Ist Homeoffice das Modell der Zukunft? Wirt-schaftsinformatik \& Management, 12, 270-272.

Van der Lippe, T., \& Lippényi, Z. (2020). Co-workers working from home and individual and team performance. New Technology, Work and Employment, 35(1), 60-79.

Van Laar, E., van Deursen, A. J., van Dijk, J. A., \& de Haan, J. (2020). Determinants of 21st-century skills and 21 st-century digital skills for workers: A systematic literature review. Sage Open, 10(1).

Vargo, D., Zhu, L., Benwell, B., \& Yan, Z. (2021). Digital Technology Use During COVID-19 Pandemic: A Rapid Review. Human Behavior and Emerging Technologies, 3(1), 13-24.

Vega, R. P., Anderson, A. J., \& Kaplan, S. A. (2015). A within-person examination of the effects of telework. Journal of Business and Psychology, 30(2), 313-323.

Waizenegger, L., McKenna, B., Cai, W., \& Bendz, T. (2020). An affordance perspective of team collaboration and enforced working from home during COVID-19. European Journal of Information Systems, 29(4), 429442.

Wang, B., Liu, Y., Qian, J., \& Parker, S. K. (2021). Achieving effective remote working during the COVID-19 pandemic: A work design perspective. Applied Psychology, 70(1), 16-59.

Wessels, C., Schippers, M. C., Stegmann, S., Bakker, A. B., van Baalen, P. J., \& Proper, K. I. (2019). Fostering flexibility in the new world of work: A model of time-spatial job crafting. Frontiers in Psychology, 10, 505.

Wohlers, C. \& Hertel, G. (2018). Longitudinal Effects of Activity-Based Flexible Office Design on Teamwork. Frontiers in Psychology, 9, 2016.

Yin, R. K. (2018). Case study research and application: Design and methods (6th ed.). Los Angeles, London: Sage. 